\title{
Controlling Molecular Mobility and Ductile-Brittle Transitions of Polycarbonate Copolymers
}

\author{
JINHUANG WU, ${ }^{1}$ CHAODONG XIAO, ${ }^{1}$ ALBERT F. YEE, ${ }^{1}$ CHRISTOPHER A. KLUG, ${ }^{2}$ JACOB SCHAEFER $^{2}$ \\ ${ }^{1}$ Macromolecular Science and Engineering, University of Michigan, Ann Arbor, Michigan 48109 \\ ${ }^{2}$ Chemistry Department, Washington University in St. Louis, St. Louis, Missouri 63130
}

Received 12 July 1999; revised 16 April 2001; accepted 19 April 2001

\begin{abstract}
To control molecular mobility and study its effects on mechanical properties, we synthesized two series of poly(ester carbonate) and polycarbonate copolymers with different linkages: $\left(\mathrm{B}_{x} \mathrm{t}\right)_{n}(x=3,5,7,9)$ and $\left(\mathrm{B}_{x} \mathrm{~T}\right)_{n}(x=1,3,5,7,9)$, where $\mathrm{t}$ represents the terephthalate, $\mathrm{T}$ represents the tetramethyl bisphenol A carbonate linkages, and B is the conventional bisphenol-A (BPA) carbonate. These two series of materials have distinct differences in their relaxation behaviors and chain mobility, as indicated by the $\pi$-flip motion of the phenylene rings in the $\mathrm{B}_{x}$ blocks. Uniaxial tensile tests of the copolymers indicate that the brittle-ductile transition (BDT) temperatures of the copolymers are correlated to whether the $\gamma$-relaxation peaks due to the $\mathrm{B}_{x}$ sequence is fully established. The materials possessing more fully established lowtemperature $\gamma$ peaks give rise to a lower BDT. Also, the locations of the $\gamma$ peaks are correlated to the ring flips of the $\mathrm{B}_{x}$ blocks of polymer chains. (C) 2001 John Wiley \& Sons, Inc. J Polym Sci Part B: Polym Phys 39: 1730-1740, 2001
\end{abstract}

Keywords: polymer mechanical properties; brittleness; polycarbonate; relaxations; polymer ductility

\section{INTRODUCTION}

Most polymeric materials exhibit significantly different deformation behaviors at different temperatures and strain rates. Certainly, for one material to be different from others, the primary cause is differences in chemical structures. Variations in chemical structures may give rise to further diversity in microscopic structures of the solid state, which may have dramatic influences on the mechanical properties of the materials. Moreover, some types of molecular motions, resulting from intrinsic intermolecular and intramolecular energetics of certain chemical structures, produce distinguishing characteristics in

Correspondence to: A. F. Yee (E-mail: afyee@imre.org.sg) Journal of Polymer Science: Part B: Polymer Physics, Vol. 39, 1730-1740 (2001) (ㅇ) 2001 John Wiley \& Sons, Inc. the properties among different materials. For amorphous polymers, the difference in the mechanical properties of the material at various temperatures and strain rates is mainly the result of interactions of the various molecular mobilities with the external stress field.

\section{$\gamma$ Relaxation and Ability to Yield: Some Phenomenological Observations}

Most glassy polymers exhibit secondary relaxation peaks below their glass-transition temperature $\left(T_{\mathrm{g}}\right)$. These sub- $T_{\mathrm{g}}$ secondary relaxation peaks, detected by dynamic mechanical spectroscopy (DMS) at a certain temperature and frequency range, are identified as $\beta, \gamma, \delta$, and so forth in order of decreasing temperature. The $\beta$ relaxation, which is closest to $T_{\mathrm{g}}$, is observable in all glassy polymers and is due to a structural relax- 
ation process. Its appearance and shape depend on the thermal history of the specimen. The $\gamma$-relaxation behavior of a glassy polymer, however, is the consequence of thermally excited specific molecular motions. (In previous work, ${ }^{1,2}$ such relaxations have been called $\beta$ relaxations.) The lowtemperature $\gamma$ relaxation has been used to explain the impact strengths of some polymeric materials. Boyer ${ }^{1}$ and Heijboer, ${ }^{2}$ after summarizing published work by various researchers on a number of polymers, concluded that there was a correlation between the low-temperature $\gamma$-relaxation peak and the impact strength of the polymeric materials. They observed that polymers possessing $\gamma$-relaxation peaks below room temperature often gave high impact strengths. For example, a material such as poly[2,2-bis(4-hydroxyphenyl) propane carbonate] (BPA-PC), having low-temperature $\gamma$-relaxation peaks, exhibits good impact strength. However, materials such as polystyrene and poly(methyl methacrylate) (PMMA), having $\gamma$-relaxation peaks higher than room temperature or without a significant peak all together, have low impact strengths.

However, not all the molecular motions contribute to the mechanical properties of polymeric materials. For example, the exceptional brittleness of poly(cyclohexyl methacrylate) led Heijboer $^{2}$ to the conclusion that side-chain motions do not contribute to energy absorption during impact tests. It was believed that the $\gamma$-relaxation peak of poly(cyclohexyl methacrylate) was the result of the boat/chair/boat conformational transformation of its pendant cyclohexyl ring. The side-chain motion was localized and, therefore, could not contribute to plastic deformation. This notion was further demonstrated by impact tests of $\operatorname{poly}(n$ propyl methacrylate) (PPMA) and PMMA. ${ }^{2}$ The former material has a low-temperature mechanical relaxation peak located around $-185^{\circ} \mathrm{C}$ at 1.0 $\mathrm{Hz}^{3}$ The latter has a peak close to room temperature at the same frequency. The existence of the low-temperature $\gamma$-relaxation peak did not enhance the impact strength of PPMA. For PMMA, the impact strength had a slight increase that began around its $\gamma$-relaxation peak temperature. This difference is thought to be due to the fact that the low-temperature mechanical loss peak of PPMA is primarily caused by the motion of its side-chain propyl group, which does not seem to play a role in the plastic deformation process. However, the increase of impact strength in PMMA was attributed to the $\gamma$-relaxation peak. It was later found by Yee and Takemori ${ }^{4}$ using dy- namic bulk relaxation that side-group motion in PMMA was actually coupled to the main chain. The coupling of the side-chain and main-chain motions in PMMA was also observed recently by solid-state NMR. ${ }^{5}$ These results suggest that the involvement of the main-chain motion in the $\gamma$-relaxation process increases the impact strength of PMMA, once the relaxation is excited, and explain why the existence of a low-temperature $\gamma$-relaxation peak alone is not sufficient to guarantee high impact strength. It is now generally recognized that only motions incorporating mainchain movements can give rise to enhanced impact strength. High impact strength in a notched specimen not sufficiently thick to produce plane strain constraint is primarily due to extensive yielding at the notch. Thus, a material with a greater propensity toward shear yielding rather than cleavage fracture (or crazing in the case of a thermoplastic) will produce a higher impact strength.

\section{$\gamma$ Relaxation and Mechanical Properties of BPA-PC and Polycarbonate Copolymers}

Because of its importance as an engineering plastic, the mechanical properties of BPA-PC have been extensively investigated by many researchers. ${ }^{6-10}$ BPA-PC is a very ductile material even at low temperatures and high strain rates. The superior ability to shear yield of BPA-PC has been generally attributed to its low-temperature mechanical $\gamma$-relaxation peak, located around $-100{ }^{\circ} \mathrm{C}$ at $1.0 \mathrm{~Hz} .^{1,2}$ More recently, it was proposed that a large-scale cooperative motion involving as many as seven repeat units is responsible for the low-temperature $\gamma$ relaxation of BPA-PC. ${ }^{11,12}$

The importance of the scale of the cooperative motion was demonstrated by a study of mechanical properties of a series of polycarbonate copolymers conducted by Xiao et al. ${ }^{13}$ They performed uniaxial tensile tests on $\left(\mathrm{B}_{x} \mathrm{t} \mathrm{T}_{x}\right)_{n}$ polycarbonate copolymers, in which $\mathrm{B}_{x}$ and $\mathrm{T}_{x}$ represent bisphenol A polycarbonate and tetramethyl bisphenol A polycarbonate blocks, respectively, where $x$ is the number of the repeat units in the blocks and $t$ is a terephthalate linkage between the blocks. As mentioned previously, BPA-PC and tetramethyl bisphenol-A (TMBPA)-PC exhibit notably different $\gamma$ relaxations and mechanical behaviors. In the copolymers, these two blocks were joined by a terephthalate linkage t. For two copolymers, $\left(\mathrm{B}_{5} \mathrm{tT}_{5} \mathrm{t}\right)_{n}$ and $\left(\mathrm{B}_{3} \mathrm{tT}_{3} \mathrm{t}\right)_{n}$, with similar $\gamma$-relaxation 
peak temperatures, it was found that the $\left(\mathrm{B}_{5} \mathrm{tT}_{5} \mathrm{t}\right)_{n}$ copolymer was capable of undergoing yielding deformation at $-40{ }^{\circ} \mathrm{C}$, whereas $\left(\mathrm{B}_{3} \mathrm{tT}_{3} \mathrm{t}\right)_{n}$ could not yield until the temperature reached approximately $50{ }^{\circ} \mathrm{C}$. These results suggested that the ability of the materials to yield depended on the length of the B block. By assuming that the $t$ linkages delimit the scale of cooperative motion, they concluded that the latter is crucial in determining the ability of the copolymers to shear yield.

From the previous discussion, it can be seen that $\gamma$ relaxations can have a significant influence on the plastic deformation behavior of materials. However, the $\gamma$ relaxations alone, in many cases, are not sufficient for us to interpret differences in the mechanical properties of various materials. It is, therefore, important to understand the nature of the molecular motion related to the $\gamma$ relaxation and how they influence the mechanical properties of the materials. For BPA-PC and its copolymers, the understanding of effects of the $\gamma$ relaxations on the mechanical properties remains on the phenomenological level despite the fact that there have been extensive studies in this area. This is partly due to the lack of a detailed picture of what gives rise to the $\gamma$ relaxations of the materials on the molecular level and partly due to a lack of understanding of how the molecular motion interacts with the stress as the latter increases. In this article, a systematic variation in the molecular architecture is used to provide more detailed information of the $\gamma$ relaxations. In turn, their influence on mechanical behavior is also clarified.

To understand the relationship of the molecular motions, $\gamma$ relaxation, and the mechanical properties of the BPA-PC-based materials, $\left(\mathrm{B}_{x} \mathrm{t}\right)_{n}$ and $\left(\mathrm{B}_{x} \mathrm{~T}\right)_{n}$ copolymers were synthesized, and uniaxial tensile tests were performed on them. These copolymers serve as ideal candidates for mechanical studies for two reasons. First, the chemical structures of the two copolymers are similar, with the only difference being the linkages, $t$ and $T$, between the $B_{x}$ blocks. The influence of the $t$ and $\mathrm{T}$ linkages on the ability of the materials to shear yield can be evaluated when the $\mathrm{B}_{x}$ block lengths are kept the same for the two copolymers. Second, in a thorough investigation of the $\gamma$-relaxation characteristics with DMS and solid-state NMR, ${ }^{14}$ we found that these two series of copolymers exhibited distinctive differences in their $\gamma$-relaxation behaviors and chain mobility. Their effects on the materials' ability to shear yield can be determined when the brittle-ductile transition (BDT) temperatures of these copolymers are compared.

\section{MATERIALS}

$\left(\mathrm{B}_{x} \mathrm{t}\right)_{n}$ and $\left(\mathrm{B}_{x} \mathrm{~T}\right)_{n}$ copolymers were synthesized by the preparation of $\mathrm{B}_{x}$ oligomers, followed by the polymerization of oligomers with terephthaloyl chloride or tetramethylbisphenol A bischloroformates. The total molecular weights were controlled by the addition of phenol. The numberaverage molecular weight $\left(M_{\mathrm{n}}\right)$, as determined by gel permeation chromatography, was higher than $20,000 \mathrm{~g} / \mathrm{mol}$ for all the copolymers. The BPA-PC was from GE Plastics.

\section{Synthesis of $\left(B_{9} T\right)_{n}$ Copolymer}

To a 1.0-L reactor equipped with a mechanical stirrer and a dropping funnel, $0.3280 \mathrm{~g}$ (3.485 $\mathrm{mmol})$ of phenol, $22.83 \mathrm{~g}(100 \mathrm{mmol})$ of bisphenol A, $16.19 \mathrm{~g}$ (160 mmol) of triethylamine, $2.0 \mathrm{~g}$ of $\mathrm{N}, \mathrm{N}$-dimethyl-4-amino pyridine (DMAP), and 350 $\mathrm{mL}$ of dichloromethane were added. The mixture was cooled with an acetone/dry-ice bath to -25 ${ }^{\circ} \mathrm{C}$. Bisphenol A bischloroformate $(28.24 \mathrm{~g}, 80$ $\mathrm{mmol}$ ), dissolved in $150 \mathrm{~mL}$ of dichloromethane, was added within $30 \mathrm{~min}$, and the reaction was continued for another $10 \mathrm{~min}$.

A second portion of triethylamine, $4.05 \mathrm{~g} \mathrm{(42.0}$ $\mathrm{mmol}$ ), in $30 \mathrm{~mL}$ of dichloromethane was then added, followed by the addition of a solution of $8.18 \mathrm{~g}$ (20 mmol) of tetramethyl bisphenol A bischloroformate in $60 \mathrm{~mL}$ of dichloromethane. The mixture was then warmed up to room temperature gradually, and a viscous mixture was obtained. The mixture was poured into a blender filled with a large quantity of isopropanol. A white precipitate was obtained after the precipitation. The polymer was dried, dissolved in dichloromethane, and reprecipitated. This purification procedure was repeated twice. Finally, $46.8 \mathrm{~g}$ of $\left(\mathrm{B}_{9} \mathrm{~T}\right)_{n}$ polycarbonate copolymer was obtained, and the yield was $90 \%$.

\section{Synthesis of Other $\left(B_{x} T\right)_{n}$ Copolymers}

The polymerization of $\left(\mathrm{B}_{3} \mathrm{~T}\right)_{n},\left(\mathrm{~B}_{5} \mathrm{~T}\right)_{n}$, and $\left(\mathrm{B}_{7} \mathrm{~T}\right)_{n}$ was similar to that of $\left(\mathrm{B}_{9} \mathrm{~T}\right)_{n}$ as described previously, with appropriate adjustments in the amounts of reactants according to stoichiometry. 


\section{Synthesis of $(\mathrm{BT})_{n}$ Copolymer}

In a 1.0-L reactor equipped with a mechanical stirrer and a dropping funnel, $0.3608 \mathrm{~g}$ (3.834 $\mathrm{mmol})$ of phenol and $31.27 \mathrm{~g}(110 \mathrm{mmol})$ of TMBPA were placed; $250 \mathrm{~mL}$ of dichloromethane was added, followed by the addition of $23.37 \mathrm{~g}$ (231 mmol) of triethylamine and $2.34 \mathrm{~g}$ of DMAP dissolved in $50 \mathrm{~mL}$ of dichloromethane. The mixture was cooled to $0{ }^{\circ} \mathrm{C}$, and $38.83 \mathrm{~g}(110 \mathrm{mmol})$ of bisphenol A bischloroformate dissolved in $120 \mathrm{~mL}$ of dichloromethane was added over $40 \mathrm{~min}$. The mixture was allowed to warm up to room temperature and then was precipitated with isopropanol. After purification, $56.3 \mathrm{~g}$ (91\% yield) of $(\mathrm{BT})_{n}$ copolymer was obtained.

\section{Synthesis of $\left(B_{3} t\right)_{n^{\prime}}\left(B_{5} t\right)_{n^{\prime}}\left(B_{7} t\right)_{n^{\prime}}$ and $\left(B_{9} t\right)_{n}$ Copolymers}

In the synthesis of $\left(\mathrm{B}_{x} \mathrm{t}\right)_{n}(x=3,5,7,9)$ copolymers, the first step of the polymerization was similar to that of $\left(\mathrm{B}_{x} \mathrm{~T}\right)_{n}$ copolymers. In the second step, stoichiometric amounts of terephthaloyl chloride dissolved in dichloromethane were added. Similarly, the copolymer was precipitated in isopropanol.

\section{EXPERIMENTAL}

The materials were dried in a vacuum oven for at least $12 \mathrm{~h}$ at $100{ }^{\circ} \mathrm{C}$ before melt processing. For the materials in powder form, an extra step was taken to ensure high-quality, void-free specimens because powders were packed together loosely, so that air pockets were very likely to be trapped in the specimen if molded directly. Therefore, the dried powders were heated in vacuo to a temperature $20-30{ }^{\circ} \mathrm{C}$ above its $T_{\mathrm{g}}$. The powder particles sintered so that the amount of trapped air was greatly reduced.

The molecular weight and distribution of the molded polymers were determined with a Waters size exclusion chromatograph with polystyrene as a standard. The results are reported in Table I.

All the specimens used in the mechanical tests were compression-molded. The dumbbell-shaped specimens were $0.125 \mathrm{in}$. thick, $0.375 \mathrm{in}$. wide, and $1 \mathrm{in}$. in gauge length and had a shoulder radius of $0.25 \mathrm{in}$. Compression moldings were performed with a Tetrahedron hot press equipped with a programmable controller, which allowed changes of temperature, pressure, and molding
Table I. Molecular Weight and $T_{\mathrm{g}}$ 's of the Copolymers

\begin{tabular}{lccc}
\hline \multicolumn{3}{c}{ First Molding } \\
\cline { 2 - 3 } Sample & $\begin{array}{c}M_{\mathrm{n}}, \\
\left(\mathrm{g} / \mathrm{mol} ; 10^{-3}\right)\end{array}$ & $\begin{array}{c}\text { Polydispersity } \\
\text { Index }\end{array}$ & $T_{\mathrm{g}}\left({ }^{\circ} \mathrm{C}\right)$ \\
\hline$\left(\mathrm{B}_{3} \mathrm{t}\right)_{n}$ & 37 & 1.9 & 169 \\
$\left(\mathrm{~B}_{5} \mathrm{t}\right)_{n}$ & 41 & 1.8 & 160 \\
$\left(\mathrm{~B}_{7} \mathrm{t}\right)_{n}$ & 30 & 1.9 & 157 \\
$\left(\mathrm{~B}_{9} \mathrm{t}\right)_{n}$ & 26 & 2.2 & 156 \\
$\mathrm{BPA} \mathrm{PC}$ & 25 & 2.2 & 149 \\
$\left(\mathrm{~B}_{9} \mathrm{~T}\right)_{n}$ & 39 & 1.6 & 154 \\
$\left(\mathrm{~B}_{7} \mathrm{~T}\right)_{n}$ & 54 & 1.6 & 158 \\
$\left(\mathrm{~B}_{5} \mathrm{~T}\right)_{n}$ & 46 & 1.7 & 159 \\
$\left(\mathrm{~B}_{3} \mathrm{~T}\right)_{n}$ & 33 & 2.2 & 160 \\
$(\mathrm{BT})_{n}$ & 54 & 1.4 & 170 \\
\hline
\end{tabular}

time at various stages. The specimens were molded at temperatures approximately $80{ }^{\circ} \mathrm{C}$ above their corresponding $T_{\mathrm{g}}{ }^{\prime} \mathrm{s}$ and cooled to $50^{\circ} \mathrm{C}$ at a rate of $20{ }^{\circ} \mathrm{C} / \mathrm{min}$. They were then removed from the hot press and cooled to room temperature. No antioxidant or mold-release agents were used to avoid possible contamination of the specimens. After releasing the specimens from the template, we polished all the edges of the specimens with fine sand paper. Molded specimens were transparent with no visible sign of crystallization. An examination of the specimens under cross-polarized light found no sign of a significant concentration of residual stress. To minimize complications due to variations in thermal history, we conducted mechanical tests within $24 \mathrm{~h}$ after compression molding.

Uniaxial tensile tests were performed with a servohydraulic mechanical testing machine (Instron model 1331) equipped with an environmental chamber. Instrumental control and data acquisition were carried out with a Hewlett-Packard computer. A specimen was mounted on the upper grips at room temperature under stroke (displacement) control. An extensometer (MTS model 632.13B-20; 0.5-in. gauge length, 15\%) was attached to the gauge section of the specimen. This was followed by the other end of the specimen being attached to the bottom grips. The machine was then switched to load control (zero load) before cooling and kept under zero load during the cooling process. The procedure was necessary to eliminate stress induced by cooling contraction. The environmental chamber was able to control the testing temperature to as low as $-130{ }^{\circ} \mathrm{C}$ with 
liquid nitrogen as the cooling medium. Several thermocouples were placed inside the chamber to monitor the temperature, including thermocouples embedded into dummy specimens with thicknesses similar to that of the test specimen. The chamber was capable of controlling the temperature fluctuation to within a range of less than \pm 2 ${ }^{\circ} \mathrm{C}$. After the chamber temperature reached the desired set point, the specimen was held for 10 min more at this temperature to establish thermal equilibrium. The control mode of the testing machine was then switched back to stroke control before the test, and the machine was placed under computer control. The crosshead speed of the tensile tests was set at $1.0 \mathrm{in} . / \mathrm{min}$. The load, displacement, and strain were recorded. Young's modulus, maximum stress (yield stress) and strain (yield strain), and initial strain rate were calculated. The uniaxial tensile tests were performed at temperatures as low as $-130{ }^{\circ} \mathrm{C}$, depending on the BDT temperatures of the materials. Three specimens were tested at each temperature.

Dipolar, rotational spin-echo ${ }^{13} \mathrm{C}$ NMR experiments were performed on $\left(\mathrm{B}_{x} \mathrm{t}\right)_{n}$ as described previously for $\left(\mathrm{B}_{x} \mathrm{~T}\right)_{n} \cdot{ }^{14}$

\section{RESULTS AND DISCUSSION}

\section{Selections of Uniaxial Tensile Test and Criteria}

It has been known that the mechanical properties of polymeric materials depend on their molecular weights, deformation rates, temperatures, and some other extrinsic elements such as the specimen geometry, thermal history, and presence of impurities and diluents. To minimize these influences, we took care to ensure that the copolymers synthesized had a molecular weight much higher than the entanglement molecular weight $\left(M_{\mathrm{e}}\right)$. For BPA-PC, $M_{\mathrm{e}}$ is about $2000-3000 .{ }^{15,16} \mathrm{As}$ shown in Table I, the molecular weights of all the materials are many times higher than the $M_{\mathrm{e}}$ of BPA-PC, assuming that the $M_{\mathrm{e}}$ of the copolymers are not significantly different from that of BPAPC. We controlled the thermal histories by molding the materials under similar conditions and, more importantly, with the same cooling procedures.

To correlate the $\gamma$ relaxations with the mechanical properties of the polymeric materials, the majority of the previous studies used impact tests (notched or unnotched specimens) to evaluate the ductility of the materials. However, the ductility obtained by impact testing may be complicated by several factors. ${ }^{17}$ First, impact tests are performed at very high speeds, so the strain rate corresponds to a frequency of several kilohertz. Second, the impact strength is very sensitive to specimen geometry, especially the size of the notch of the test specimen. It has been shown that different materials may have dissimilar notch sensitivities. ${ }^{18}$ This means that the impact strengths of the notched specimens may not reveal the intrinsic properties of the tested materials. These factors often lead to ambiguous and indeed unreliable conclusions. The evaluation of ductility of a material can also be accomplished by uniaxial tensile testing and measuring the ultimate strain. However, complexity arises because the ultimate engineering strain depends on the molecular weight of the material, surface flaws and, in the case of materials capable of necking, the specimen geometry. In addition, the mechanical behavior in the very large strain regime is very unlikely to be related to the $\gamma$-relaxation characteristics. For these reasons, we chose simple uniaxial tensile tests at various temperatures and only relate the ability to shear yielding of materials with their $\gamma$ relaxations. Also, the strain rate applied in the tensile tests is approximately $10^{-2} / \mathrm{s}$, which corresponds to approximately $1.0 \mathrm{~Hz}$ in the DMS measurement. ${ }^{19}$

For each polymer, uniaxial tensile tests were performed at various temperatures until a temperature was found at which brittle behavior was observed. Figure 1 shows the engineering stressstrain curves of BPA-PC at various temperatures. They change substantially with temperature. At room temperature, the material gives a typical stress-strain curve with a notable yield

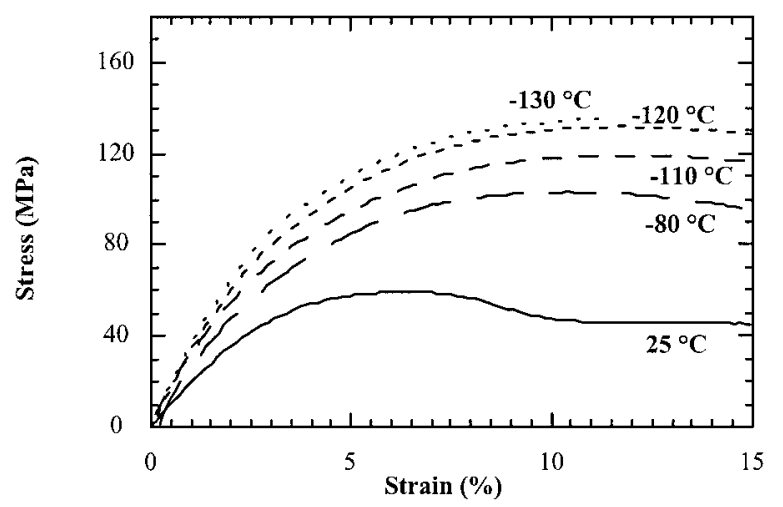

Figure 1. Stress-strain curves of BPA-PC at different temperatures $(\epsilon=0.01 / \mathrm{s})$. 


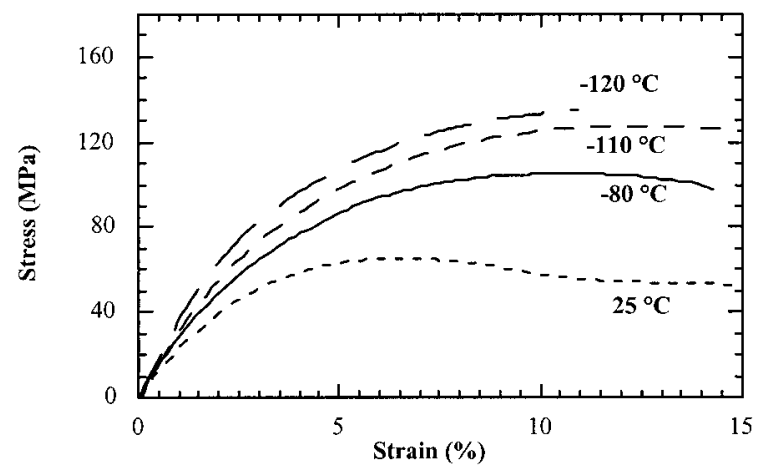

Figure 2. Stress-strain curves of $\left(\mathrm{B}_{9} \mathrm{t}\right)_{n}$ at different temperatures $(\epsilon=0.01 / \mathrm{s})$.

point, followed by a post-yield-stress drop. However, the stress-strain curves obtained at low temperatures do not exhibit the typical postyield-stress drop. Instead, the stresses simply reach plateaus as the strains increase. Although sometimes a slight decrease of stress was observed, these were not nearly as prominent as that observed at room temperature. As a result, yielding is considered to have occurred at a low temperature if the stress no longer increases. This is consistent with the conventional definition, which states that, at the yield point of a stress-strain curve, a condition momentarily exists wherein the deformation proceeds at a constant strain rate but the time rate of the change of stress is zero. That is, the yield point has the appearance of a momentary condition of pure viscous flow. ${ }^{20-22}$ In our study, the BDT temperature at a certain strain rate is defined as the temperature at which the material can no longer yield.

\section{Brittle Ductile Transition (BDT) Temperature of BPA-PC}

Uniaxial tensile tests of BPA-PC were conducted at $25,-80,-110,-12$, and $-130{ }^{\circ} \mathrm{C}$. The stressstrain curves, shown in Figure 1, indicate that a prominent post-yield-stress drop occurred at temperatures as low as $-80{ }^{\circ} \mathrm{C}$. No notable yield stress drop was observed when the material was tested at $-110{ }^{\circ} \mathrm{C}$ or lower. A significant yield stress drop was always accompanied by necking of the material in the gauge section. In the case of no observable necking, the yield stress simply reached a plateau, and a very slight drop was found at times. This was usually followed by the immediate fracture of the specimen in the gauge section. A similar sequence of deformation events

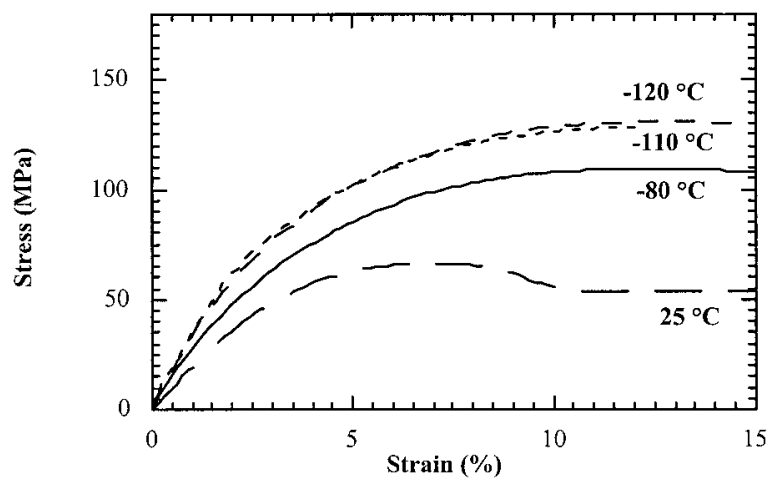

Figure 3. Stress-strain curves of $\left(\mathrm{B}_{7} \mathrm{t}\right)_{n}$ at different temperatures $(\epsilon=0.01 / \mathrm{s})$.

was observed in the uniaxial tensile tests of amorphous PET at various temperatures by Foot et al. ${ }^{23}$ They described this type of yielding behavior as ductile fracture in which plastic deformation led to a load drop but could not stabilize into shear bands. The yield strain at low temperatures is found to be higher than that measured at room temperature. However, the precise yield strains cannot be determined in these tests. A similar trend was also observed by other researchers. ${ }^{9,23}$

Four specimens of BPA-PC were tested at $-120{ }^{\circ} \mathrm{C}$, and three of them exhibited yield. Eleven specimens were tested at $-130{ }^{\circ} \mathrm{C}$, and eight of them did not yield, whereas the rest exhibited mixed mode behavior. In this manner, it was possible to conclude that the BDT temperature for BPA-PC is $-120 /-130{ }^{\circ} \mathrm{C}$ at a strain rate of $10^{-2} / \mathrm{s}$ with this particular specimen geometry and thermal history. The yield stress at $-120^{\circ} \mathrm{C}$ is around $133 \mathrm{MPa}$, very close to the $130 \mathrm{MPa}$ obtained by Bauwens-Crowet et al. ${ }^{24}$ using uniaxial tensile test with a thicker specimen $(5 \mathrm{~mm}$

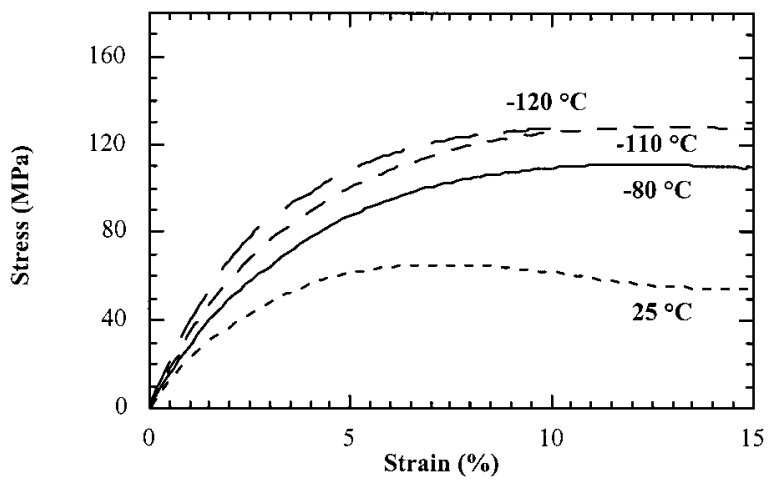

Figure 4. Stress-strain curves of $\left(\mathrm{B}_{5} \mathrm{t}\right)_{n}$ at different temperatures $(\epsilon=0.01 / \mathrm{s})$ 


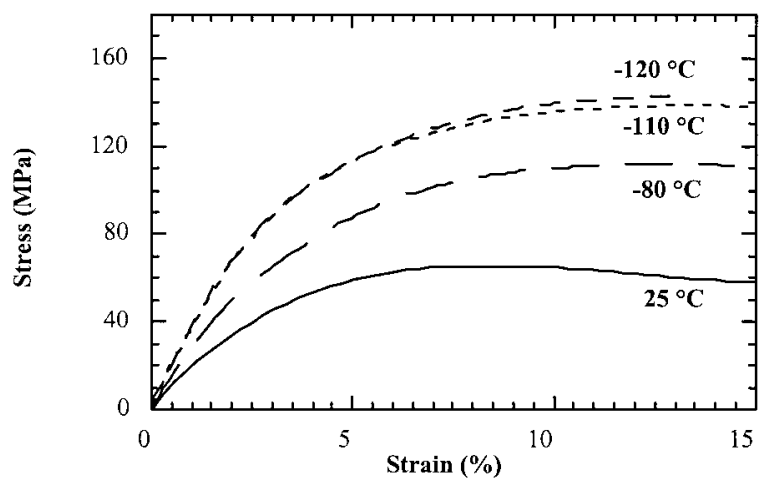

Figure 5. Stress-strain curves of $\left(\mathrm{B}_{3} \mathrm{t}\right)_{n}$ at different temperatures $(\epsilon=0.01 / \mathrm{s})$.

vs $3.2 \mathrm{~mm}$ in this study) and a lower strain rate $\left(4.2 \times 10^{-3} / \mathrm{s}\right.$ vs $\left.1.0 \times 10^{-2} / \mathrm{s}\right)$. This value is also similar to the yield stress of $121 \mathrm{MPa}$ at $-123{ }^{\circ} \mathrm{C}$ with a thin film $(5 \mathrm{mil}=0.13 \mathrm{~mm})$ at a strain rate of $1.7 \times 10^{-4} / \mathrm{s}$ by Kastelic and Baer. ${ }^{25}$ They also observed that in a nitrogen atmosphere, the material was on the verge of yielding at $-123^{\circ} \mathrm{C}$.

\section{BDT Temperatures of $\left(B_{x} t\right)_{n}$ and $\left(B_{x} T\right)_{n}$ Copolymers}

The stress-strain curves of $\left(\mathrm{B}_{x} \mathrm{t}\right)_{n}$ copolymers at various temperatures are shown in Figures 2-5. As listed in Table II, tensile tests of $\left(\mathrm{B}_{x} \mathrm{t}\right)_{n}(x=3$, $5,7,9)$ copolymers show that the BDT temperatures for all the copolymers are $-110 /-120^{\circ} \mathrm{C}$, which is independent of the average block length $x$. Again, the strain rate of the tests is approximately $1.0 \times 10^{-2} / \mathrm{s}$. The stress-strain curves of $\left(\mathrm{B}_{x} \mathrm{~T}\right)_{n}$ copolymers at different temperatures are shown in Figures $6-10$. For $\left(\mathrm{B}_{x} \mathrm{~T}\right)_{n}(x=1,3,5,7$, 9) copolymers, the BDT temperatures are $-30 /$ $-40,-50 /-60-90 /-100,-110 /-120$, and $-110 /$

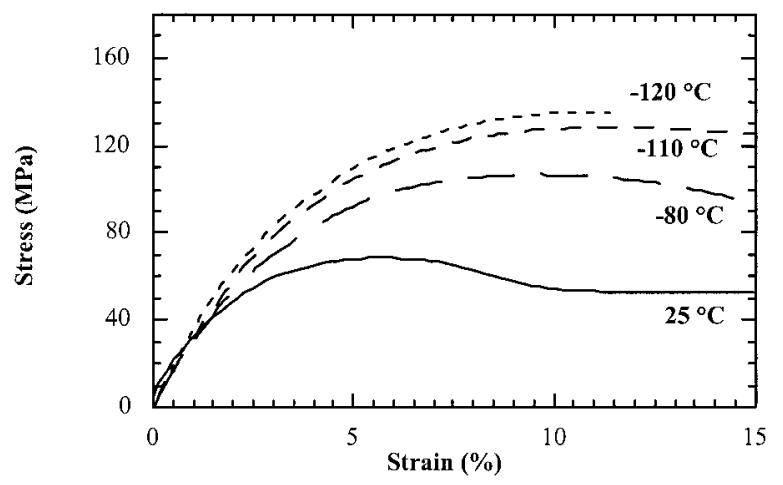

Figure 6. Stress-strain curves of $\left(\mathrm{B}_{9} \mathrm{~T}\right)_{n}$ at different temperatures $(\epsilon=0.01 / \mathrm{s})$.

$-120^{\circ} \mathrm{C}$, respectively, as summarized in Table II. The yield stresses for $\left(\mathrm{B}_{x} \mathrm{t}\right)_{n}$ copolymers at $-110^{\circ}$ range from 128 to $134 \mathrm{MPa}$, values which are slightly higher than that of BPA-PC (122 MPa) at the same temperature and strain rate. For $\left(\mathrm{B}_{x} \mathrm{~T}\right)_{n}$ copolymers, only $\left(\mathrm{B}_{7} \mathrm{~T}\right)_{n}$ and $\left(\mathrm{B}_{9} \mathrm{~T}\right)_{n}$ are capable of yielding at $-110{ }^{\circ} \mathrm{C}$, and their corresponding yield stresses are 133 and $131 \mathrm{MPa}$, respectively. The relative trend of the yield stresses of the copolymers at $-110^{\circ} \mathrm{C}$ is the same as the changes at room temperature, which shows that yield stresses of copolymers are generally higher than that of BPA-PC.

The BDT temperatures of the copolymers show that the insertion of $\mathrm{t}$ and $\mathrm{T}$ units have very different effects on the mechanical properties of the materials. The BDT temperatures of $\left(\mathrm{B}_{x} \mathrm{t}\right)_{n}$ copolymers are slightly higher than that of BPA$\mathrm{PC}$, but the difference is not very significant. Their BDT temperatures are in the same range of $-110 /-120{ }^{\circ} \mathrm{C}$, independent of the $\mathrm{B}_{x}$ block lengths. Although further experiments may be

Table II. BDT Temperatures and Some Mechanical Properties of the Copolymers $(\epsilon=0.01 / \mathrm{s})$

\begin{tabular}{|c|c|c|c|}
\hline Sample & $\begin{array}{c}\text { BDT Temperature } \\
\left({ }^{\circ} \mathrm{C}\right)\end{array}$ & $\begin{array}{l}\text { Young's Modulus } \\
\text { (GPa) }\end{array}$ & Yield Stress (MPa) \\
\hline$\left(\mathrm{B}_{3} \mathrm{t}\right)_{n}$ & $-110 /-120$ & $4.0\left(\right.$ at $\left.-110{ }^{\circ} \mathrm{C}\right)$ & $134\left(\right.$ at $\left.-110{ }^{\circ} \mathrm{C}\right)$ \\
\hline$\left(\mathrm{B}_{5} \mathrm{t}\right)_{n}$ & $-110 /-120$ & $3.8\left(\right.$ at $\left.-110{ }^{\circ} \mathrm{C}\right)$ & $130\left(\right.$ at $\left.-110^{\circ} \mathrm{C}\right)$ \\
\hline$\left(\mathrm{B}_{7} \mathrm{t}\right)_{n}$ & $-110 /-120$ & $3.7\left(\right.$ at $\left.-110^{\circ} \mathrm{C}\right)$ & $132\left(\right.$ at $\left.-110^{\circ} \mathrm{C}\right)$ \\
\hline$\left(\mathrm{B}_{9} \mathrm{t}\right)_{n}$ & $-110 /-120$ & $3.5\left(\right.$ at $\left.-110{ }^{\circ} \mathrm{C}\right)$ & $128\left(\right.$ at $\left.-110^{\circ} \mathrm{C}\right)$ \\
\hline BPA-PC & $-120 /-130$ & $3.8\left(\right.$ at $\left.-120^{\circ} \mathrm{C}\right)$ & $133\left(\right.$ at $\left.-120^{\circ} \mathrm{C}\right)$ \\
\hline$\left(\mathrm{B}_{9} \mathrm{~T}\right)_{n}$ & $-110 /-120$ & $3.7\left(\right.$ at $\left.-110^{\circ} \mathrm{C}\right)$ & $131\left(\right.$ at $\left.-110^{\circ} \mathrm{C}\right)$ \\
\hline$\left(\mathrm{B}_{7} \mathrm{~T}\right)_{n}$ & $-110 /-120$ & $3.8\left(\right.$ at $\left.-110^{\circ} \mathrm{C}\right)$ & $133\left(\right.$ at $\left.-110^{\circ} \mathrm{C}\right)$ \\
\hline$\left(\mathrm{B}_{5} \mathrm{~T}\right)_{n}$ & $-90 /-100$ & $3.4\left(\right.$ at $\left.-90^{\circ} \mathrm{C}\right)$ & $121\left(\right.$ at $\left.-90^{\circ} \mathrm{C}\right)$ \\
\hline$\left(\mathrm{B}_{3} \mathrm{~T}\right)_{n}$ & $-50 /-60$ & 2.9 (at $\left.-50^{\circ} \mathrm{C}\right)$ & $104\left(\right.$ at $\left.-50^{\circ} \mathrm{C}\right)$ \\
\hline$(\mathrm{BT})_{n}$ & $-30 /-40$ & $2.8\left(\right.$ at $\left.-30{ }^{\circ} \mathrm{C}\right)$ & $103\left(\right.$ at $\left.-30^{\circ} \mathrm{C}\right)$ \\
\hline
\end{tabular}




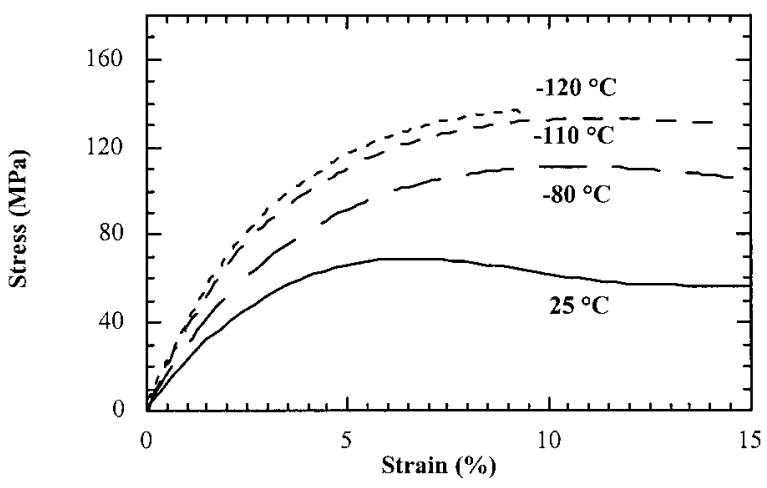

Figure 7. Stress-strain curves of $\left(\mathrm{B}_{7} \mathrm{~T}\right)_{n}$ at different temperatures $(\epsilon=0.01 / \mathrm{s})$.

required to distinguish between the minor differences in the BDT temperatures among the $\left(\mathrm{B}_{x} \mathrm{t}\right)_{n}$ copolymers, the results indicate that the incorporation of $\mathrm{t}$ units into bisphenol A polycarbonate has a minimal influence on the BDT temperatures. In another study, thin-film deformation of $\left(\mathrm{B}_{x} \mathrm{t}\right)_{n}$ copolymers also showed that the transition from diffuse to localized shear near the $\gamma$-relaxation temperature was similar between BPA-PC and $\left(\mathrm{B}_{x} \mathrm{t}\right)_{n}$ copolymers. ${ }^{16}$

However, the introduction of $\mathrm{T}$ units into bisphenol A polycarbonate causes dramatic changes in the BDT temperatures. The ability for the material to undergo ductile yielding declines as the $\mathrm{T}$ content increases. Changes in average block lengths from $x=1$ to $x=9$ result in materials ranging from relatively brittle $(\mathrm{BT})_{n}$ to very ductile $\left(\mathrm{B}_{9} \mathrm{~T}\right)_{n}$ behavior. Nonetheless, it can be seen that the alternating copolymer $(\mathrm{BT})_{n}$ is still more ductile than TMBPA-PC, which cannot yield at all at room temperature at a strain rate as low as $7 \times 10^{-4} / \mathrm{s} .{ }^{19}$ For $\left(\mathrm{B}_{x} \mathrm{~T}\right)_{n}$ copolymers, further in-

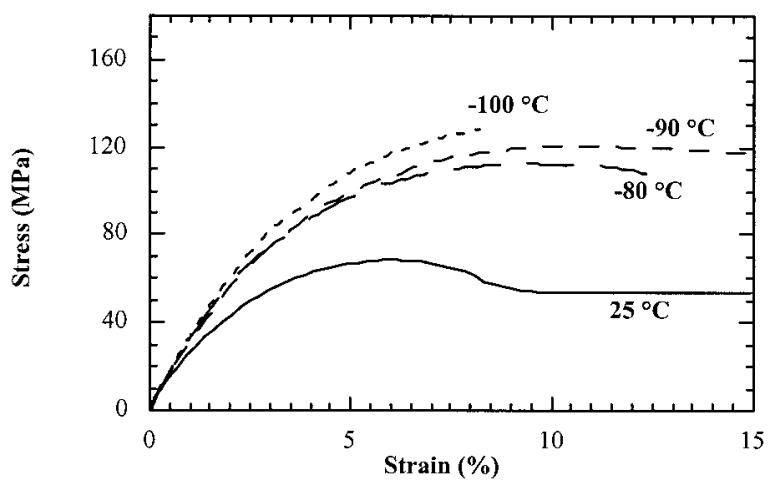

Figure 8. Stress-strain curves of $\left(\mathrm{B}_{5} \mathrm{~T}\right)_{n}$ at different temperatures $(\epsilon=0.01 / \mathrm{s})$.

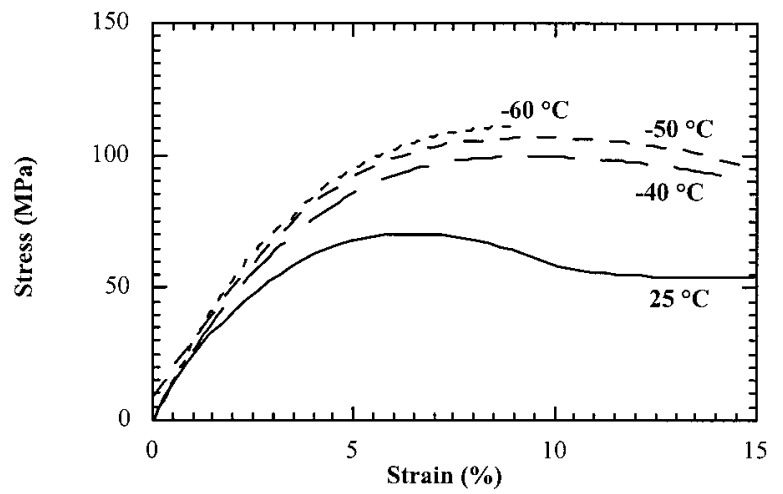

Figure 9. Stress-strain curves of $\left(\mathrm{B}_{3} \mathrm{~T}\right)_{n}$ at different temperatures $(\epsilon=0.01 / \mathrm{s})$.

creases of bisphenol A polycarbonate block lengths make the materials more ductile, and their BDT temperatures are similar to $\left(\mathrm{B}_{x} \mathrm{t}\right)_{n}$ and BPA-PC when the average block lengths reach seven and nine.

\section{BDT Temperatures and Molecular Motions}

On the molecular level, the variation of the BDT temperatures of $\left(\mathrm{B}_{x} \mathrm{t}\right)_{n}$ and $\left(\mathrm{B}_{x} \mathrm{~T}\right)_{n}$ copolymers can be viewed in terms of their differences in chain mobility. A reflection of the chain mobility is how easily the phenylene rings can flip. To this end, solid-state NMR of the copolymers by the dipolar rotational spin echo (DRSE) technique was performed. The results are shown in Figures 11 and 12. These results show that the phenylene rings in $\mathrm{B}_{x}$ blocks of the $\left(\mathrm{B}_{x} \mathrm{t}\right)_{n}$ copolymers flip faster than $10 \mathrm{kHz}$ at room temperature, and their motions are independent of the $\mathrm{B}_{x}$ block lengths $x$, as indicated by the sideband ratios shown in Figure 11 (the higher the sideband ratio is, the less mo-

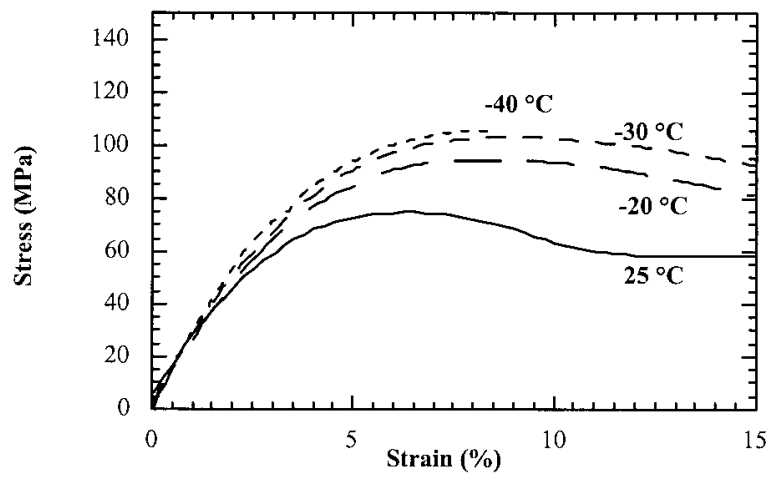

Figure 10. Stress-strain curves of $(\mathrm{BT})_{n}$ at different temperatures $(\epsilon=0.01 / \mathrm{s})$. 


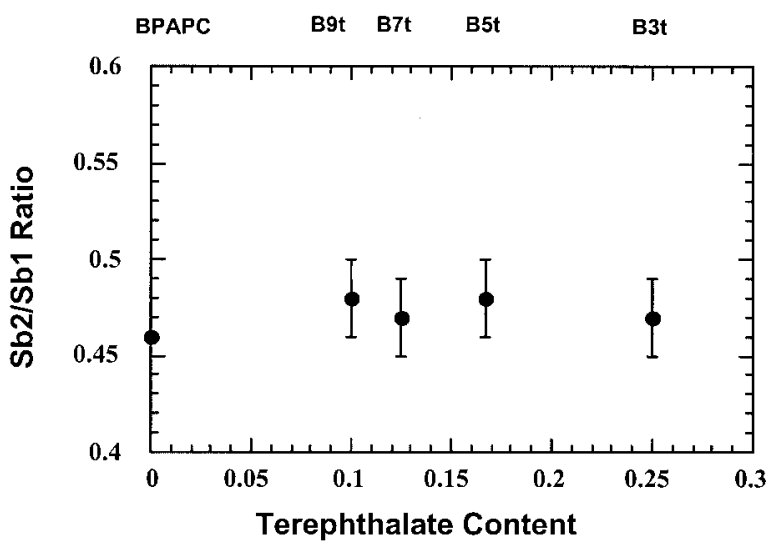

Figure 11. Sideband ratios of phenylene rings in BPA units of $\left(\mathrm{B}_{x} \mathrm{t}\right)_{n}$ copolymers.

bile the phenylene ring is). In other words, the presence of the $t$ unit does not affect the motion of the phenylene rings. The motions of the phenylene rings in $\left(\mathrm{B}_{x} \mathrm{~T}\right)_{n}$ chains, however, are different depending on the block length $x$. Solid-state NMR results indicate that the tetramethylbisphenol A unit $\mathrm{T}$ does not flip at a significant frequency at room temperature. Furthermore, the $\pi$-flip motion of the phenylene rings in $\mathrm{B}_{x}$ block is hindered by the $\mathrm{T}$ unit, as indicated by the sideband ratios in Figure 12. As the block length $x$ increases to seven and nine repeat units, the sideband ratios approach that of BPA-PC. ${ }^{14}$

DMS studies of $\left(\mathrm{B}_{x} \mathrm{t}\right)_{n}(x=3,5,7,9)$ and $\left(\mathrm{B}_{x} \mathrm{~T}\right)_{n}$ $(x=1,3,5,7,9)$ copolymers show that like BPA$\mathrm{PC}$, all $\left(\mathrm{B}_{x} \mathrm{t}\right)_{n}$ copolymers have low-temperature $\gamma$-relaxation peaks located at approximately the same temperature $\left(-100{ }^{\circ} \mathrm{C}\right.$ at $\left.1.0 \mathrm{~Hz}\right)$. As for $\left(\mathrm{B}_{x} \mathrm{~T}\right)_{n}$ copolymers, all of them have the peak located around $-20^{\circ} \mathrm{C}$, whereas the intensity of the low-temperature peak around $-100{ }^{\circ} \mathrm{C}$ increases

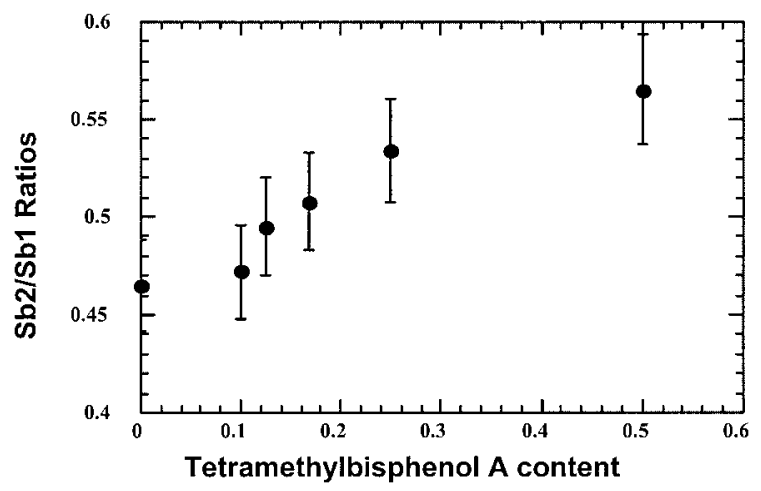

Figure 12. Sideband ratios of phenylene rings in BPA units of $\left(\mathrm{B}_{x} \mathrm{~T}\right)_{n}$ copolymers.

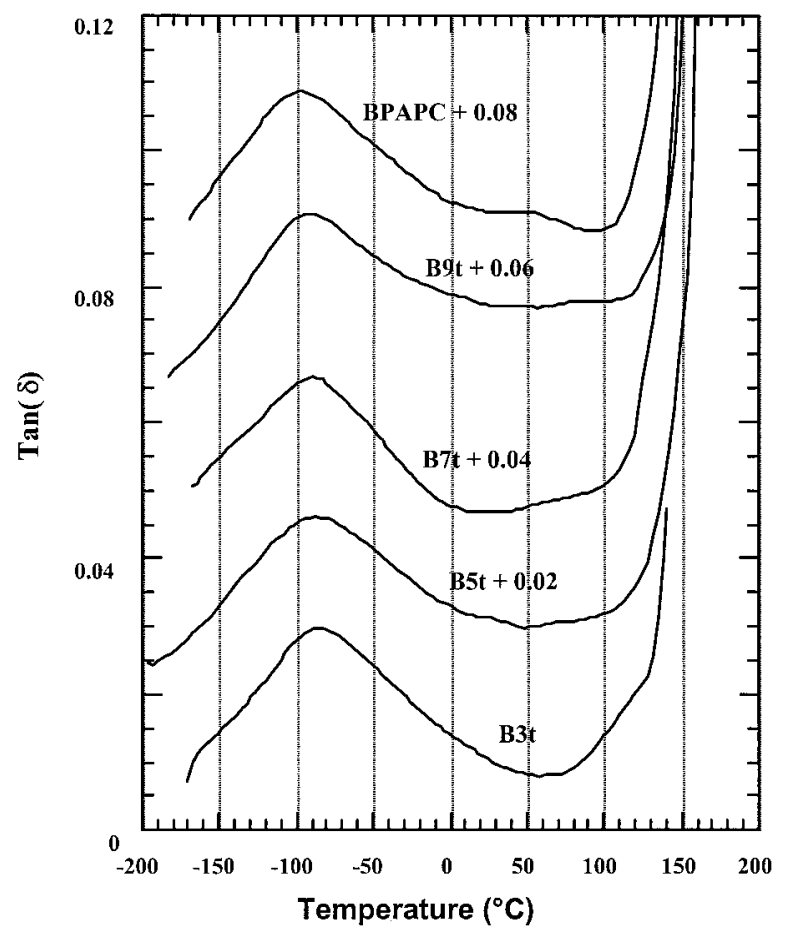

Figure 13. DMS of $\left(\mathrm{B}_{x} \mathrm{t}\right)_{n}$ copolymers $(x=3,5,7,9)$ at $1.0 \mathrm{~Hz}^{14}$

as the block lengths increase ${ }^{14}$ Clearly, the locations of the $\gamma$-relaxation peaks of the copolymers correlate with the $\pi$-flip motions of the phenylene rings in their corresponding $\mathrm{B}_{x}$ blocks. These DMS data, ${ }^{14}$ shown in Figures 13 and 14, are reproduced here for convenience of discussion.

The materials used in the solid-state NMR and DMS studies have monodispersed block $\mathrm{B}_{x}$ lengths. However, the $\left(\mathrm{B}_{x} \mathrm{t}\right)_{n}$ and $\left(\mathrm{B}_{x} \mathrm{~T}\right)_{n}$ copolymers used in the tensile tests have a broad block length distribution with a number-average block length $x$. The mechanical behavior of the polymers is not expected to be sensitive to the block size distribution. This is because the mechanical deformation process in glassy polymers involves dynamic fluctuations that typically encompass many neighboring chains and many repeat units along each chair. ${ }^{26}$ Consequently, deviations from the mean block length will not have significant effects on the fluctuation or macroscopic mechanical behavior.

We proposed that the $\pi$-flip motion of the phenylene rings in $\mathrm{B}_{x}$ blocks of the $\left(\mathrm{B}_{x} \mathrm{t}\right)_{n}$ and $\left(\mathrm{B}_{x} \mathrm{~T}\right)_{n}$ copolymers can be used as an indicator of the mobility of the $\mathrm{B}_{x} \mathrm{t}$ and $\mathrm{B}_{x} \mathrm{~T}$ chains. ${ }^{14}$ This is because the $\pi$-flip motion of the phenylene rings is the result of the movements of their surrounding 


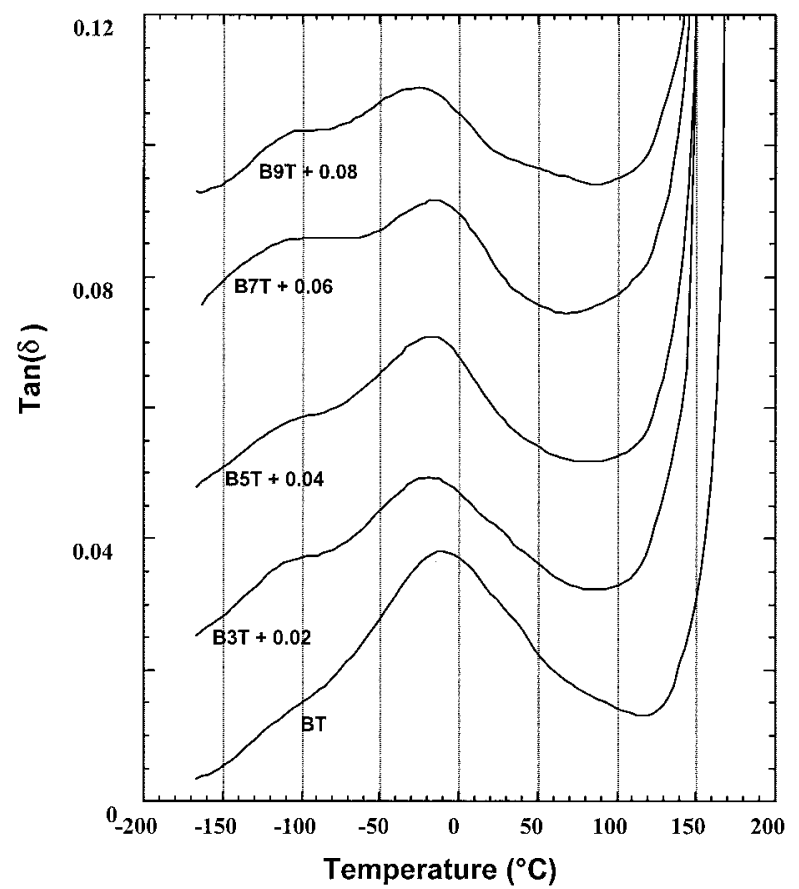

Figure 14. DMS of $\left(\mathrm{B}_{x} \mathrm{~T}\right)_{n}$ copolymers $(x=1,3,5,7$, 9) at $1.0 \mathrm{~Hz} .{ }^{14}$

chains, ${ }^{27}$ as shown schematically in Figure 15. Furthermore, it is the motions of polymer chains that give rise to the $\gamma$-relaxation peaks. In other words, there is a correlation between the macroscopic motions responsible for the $\gamma$-relaxation peaks and the phenylene ring $\pi$-flip motion on the molecular level. The correlation is further strengthened by the fact that the phenylene ring $\pi$ flip of $15 \mathrm{kHz}$ at room temperature $\left(27^{\circ} \mathrm{C}\right)$ is equivalent to $1.0 \mathrm{~Hz}$ at $-90{ }^{\circ} \mathrm{C}$, assuming an activation energy of $9.0 \mathrm{kcal} / \mathrm{mol}$. For BPA-PC, its low-temperature $\gamma$-relaxation peak is located around $-100{ }^{\circ} \mathrm{C}$ at $1.0 \mathrm{~Hz}$.

For BPA-PC and $\left(\mathrm{B}_{x} \mathrm{t}\right)_{n}$ copolymers, the similarity in the propensity to yield supports the notion that the low-temperature $\gamma$-relaxation peak is important to the yield behavior of the polymers. For the $\left(\mathrm{B}_{x} \mathrm{~T}\right)_{n}$ copolymers, the decrease of the BDT temperatures coincides well with the intensity increase of the low-temperature $\gamma$-relaxation peak, which is an indication of the gradual recovery of the seven-unit motions in BPA-PC. ${ }^{12}$ For $\left(\mathrm{B}_{7} \mathrm{~T}\right)_{n}$ and $\left(\mathrm{B}_{9} \mathrm{~T}\right)_{n}$ copolymers, their BDT temperatures are similar to BPA-PC and $\left(\mathrm{B}_{x} \mathrm{t}\right)_{n}$ copolymers as their low-temperature $\gamma$-relaxation peaks recover more of the characteristics of the $\gamma$ peak in BPA-PC.

From the uniaxial tensile tests and solid-state NMR results, it can be seen that the polymer chains with higher mobility have lower BDT temperatures. The presence of extensive main-chain molecular motions facilitates plastic deformation through two separate mechanisms, both proposed by Chen et al. ${ }^{28}$ The first one is to lower the yield stress so that it is below the critical stress at which brittle failure of the material occurs. The second mechanism is to increase the craze stress by collapsing the nanovoids so that they do not develop into craze initiation sites. ${ }^{26,28-30}$ The combination of the two processes makes the material more resistant to fracture. This proposition is generally applicable to many aromatic engineering plastics, in which extensive main-chain motions are likely to be available.

On the molecular level, recent molecular simulation work by Yang et al. ${ }^{31}$ shows that macroscopic deformation behavior of the amorphous material is determined synergistically by its nonequilibrium nature, thermal motions, and mechanical work. They demonstrate that conformational changes and the nonconformational structural changes induced by input mechanical and thermal energies provide a local mechanism for stress relief. The extensive molecular motions make conformational and nonconformational structural changes easier, leading to lower BDT temperatures.

\section{SUMMARY}

Mechanical properties of BPA-PC, $\left(\mathrm{B}_{x} \mathrm{t}\right)_{n}$, and $\left(\mathrm{B}_{x} \mathrm{~T}\right)_{n}$ copolymers have been characterized by uniaxial tensile tests from $-130{ }^{\circ} \mathrm{C}$ to room temperature. The $\left(\mathrm{B}_{x} \mathrm{t}\right)_{n}(x=3,5,7,9)$ copolymers have similar BDT temperature at $-120 /-110{ }^{\circ} \mathrm{C}$, which are very close to that of BPA-PC $(-130 /$ $\left.-120{ }^{\circ} \mathrm{C}\right)$. For $\left(\mathrm{B}_{x} \mathrm{~T}\right)_{n}$ copolymers, the BDT tem-

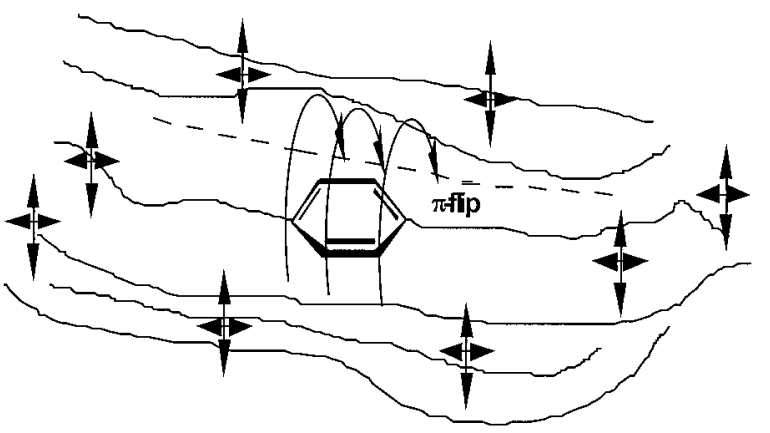

Figure 15. Phenylene ring $\pi$-flip and chain movement. 
peratures increase as the block length decreases. Their BDT temperatures fall from $-30 /-40$ to $-120 /-110{ }^{\circ} \mathrm{C}$ when the average $\mathrm{B}_{x}$ block length increases from one to nine repeat units.

The similarity in the characteristics of the $\gamma$-relaxation peaks among $\left(\mathrm{B}_{x} \mathrm{t}\right)_{n}$ copolymers and BPA-PC corresponds to the similarities in their BDT temperatures. However, the BDT temperatures of $\left(\mathrm{B}_{x} \mathrm{~T}\right)_{n}$ copolymers decrease to $-120 /-110$ ${ }^{\circ} \mathrm{C}$ only when a low-temperature $\gamma$-relaxation peak similar to that of BPA-PC is observed.

The polymer chains with higher mobility indicated by the phenylene ring $\pi$-flip motion give rise to lower BDT temperatures, which establishes the propensity for the material to yield on the molecular level.

This work was supported by grants from the National Science Foundation (NSF) (DMR-9422049 and DMR9729734).

\section{REFERENCES AND NOTES}

1. Boyer, R. F. Polym Eng Sci 1968, 8, 161.

2. Heijboer, J. J Polym Sci Part C: Polym Symp 1968, $16,3755$.

3. Hoff, E. A. W.; Robinson, D. W.; Willbourn, A. H. J Polym Sci 1955, 18, 101.

4. Yee, A. F.; Takemori, M. T. J Polym Sci 1982, 20, 205.

5. Schmidt-Rohr, K.; Kulik, A. S.; Beckham, H. W.; Ohlemacher, A.; Pawelzik, U.; Boeffel, C.; Spiess, H. W. Macromolecules 1994, 27, 4733.

6. Robertson, R. E. J Appl Polym Sci 1963, 7, 443.

7. Golden, J. H.; Hammant, B. L.; Hazell, E. A. J Appl Polym Sci 1967, 11, 1571.

8. Legrand, D. G. J Appl Polym Sci 1969, 13, 2129.

9. Roe, J. M.; Baer, E. Int J Polym Mater 1972, 1, 133.
10. Yee, A. F.; DeTorres, P. D. Polym Eng Sci 1974, 14, 691.

11. Jho, J. Y.; Yee, A. F. Macromolecules 1991, 24, 1905.

12. Xiao, C.; Yee, A. F. Macromolecules 1992, 25, 6800.

13. Xiao, C.; Jho, J. Y.; Yee, A. F. Macromolecules 1994, 27, 2761.

14. Klug, C.; Wu, J.; Xiao, C.; Yee, A. F.; Schaefer, J. Macromolecules 1997, 30, 6302.

15. Prevorsek, D. C.; De Bona, B. T. J Macromol Sci Phys 1986, 25, 515.

16. Plummer, C. J. G.; Soles, C. L.; Xiao, C.; Wu, J.; Kausch, H. H.; Yee, A. F. Macromolecules 1995, 28, 7157.

17. Nielsen, L. E. Mechanical Properties of Polymers; Reinhold: New York, 1962.

18. Vincent, P. I. Polymer 1974, 15, 111.

19. Jho, J. Y. Cooperative Molecular Motions in Bisphenol A Polycarbonate. Ph.D. Thesis, University of Michigan, 1990.

20. Roetling, J. A. Polymer 1965, 6, 311.

21. Roetling, J. A. Polymer 1965, 6, 615.

22. Bauwens-Crowet, J. C.; Bauwens, J.-C.; Homes, G. J Polym Sci 1969, 7, 735.

23. Foot, J. S.; Truss, R. W.; Ward, I. M.; Duckett, R. A. J Macromol Mater Sci 1987, 22, 1437.

24. Bauwens-Crowet, J. C.; Bauwens, J.-C.; Homes, G. J Mater Sci 1972, 7, 176.

25. Kastelic, J. R.; Baer, E. J Macromol Sci Phys 1973, 7, 679 .

26. Liu, J.; Yee, A. F. Macromolecules 2000, 33, 1338.

27. Whitney, D.; Yaris, R. Macromolecules 1997, 30, 1741.

28. Chen, L.; Yee, A. F.; Goetz, J.; Schaefer, J. Macromolecules 1998, 31, 5371.

29. Hristov, H. A.; Yee, A. F.; Gidley, D. W. Polymer 1994, 35, 3604.

30. Hristov, H. A.; Yee, A. F.; Gidley, D. W. Polymer 1994, 35, 4287.

31. Yang, L.; Srolovitz, D.; Yee, A. F. J Chem Phys 1997, 107, 4396. 